\title{
Originals
}

\section{Treatment of Severe Diabetic Ketoacidosis}

\author{
A Comparative Study of Two Methods \\ J. A. Lutterman, A. A. J. Adriaansen, and A. van 't Laar \\ Department of Internal Medicine, St. Radboud Hospital, University of Nijmegen, The Netherlands
}

\begin{abstract}
Summary. Patients with severe diabetic ketoacidosis $(\mathrm{pH}<7.10)$ were treated according to two protocols. Protocol I consisted of high-dose insulin therapy by intravenous and intramuscular injections and bicarbonate infusion and was used in the first 12 patients; they received an average of $260 \mathrm{U}$ insulin and $167 \mathrm{mmol}$ bicarbonate in the first $6 \mathrm{~h}$ of treatment. Protocol II consisted of low-dose continuous intravenous insulin therapy, $8 \mathrm{U} /$ hour, without bicarbonate in a further 12 patients. Rehydration and potassium-supplementation were the same in both methods. Basal data of both groups were not significantly different. The fall of plasma glucose concentration, rise in arterial $\mathrm{pH}$ and decrease in 3-hydroxybutyrate were similar in the two groups. The mean time to achieve a $\mathrm{pH} \geqslant 7.30$ was 6.8 hours in the high-dose group and 7.6 hours in the low-dose group $(\mathrm{p}>0.10)$. Potassium supplementation and potassium concentration during both treatments were the same. During the low-dose treatment the mean ( \pm SD) plasma insulin concentration was $121 \pm 46 \mu \mathrm{U} /$ $\mathrm{ml}$. The presence of insulin binding antibodies did not result in lower free insulin concentrations. Thus, in the treatment of severe ketoacidosis continuous intravenous therapy with low-dose insulin is as effective as high-dose therapy and bicarbonate-administration is probably unnecessary.
\end{abstract}

Key words: Diabetic ketoacidosis, high-dose insulin therapy, low-dose intravenous insulin, free insulin concentration, bicarbonate therapy.

The treatment of diabetic ketoacidosis with lowdoses of insulin has become increasingly popular following a publication of Alberti et al. in 1973 [1]. This new treatment differs from the conventional method not only in the size of the insulin dose, but also in the fact that the dose employed is no longer related to the plasma glucose level: insulin is now supplied according to a previously established scheme in a fixed dose.

The efficacy of low-dose treatment has been convincingly demonstrated in many publications despite differences in insulin dosage and route of administration [2-12]. Three studies have been published in which the low-dose treatment has been compared with the high-dose treatment $[6,9,12]$ and in only two reports the effects of both methods have been studied in a prospective way $[9,12]$. Moreover, all studies describing the effects of low-dose insulin therapy included patients with only a slight degree of ketoacidosis. As a consequence the mean degree of acidosis in these groups of patients was not very severe.

From 1974 on patients with a severe ketoacidosis have been treated by us according to a uniform protocol: in the first two years with high-dose insulin therapy and with bicarbonate when the $\mathrm{pH}$ was below 7.0, and from 1976 on with low-dose insulin therapy without bicarbonate. The present report compares the results of both treatments.

\section{Methods}

\section{Design of the Study}

The diagnosis of diabetic ketoacidosis was based on clinical grounds, on the demonstration of hyperglycaemia and on positive ketone reactions in plasma and urine (Ketur-test, Boehringer).

The ketoacidosis was considered as severe, when the $\mathrm{pH}$ in arterial blood was 7.10 or lower.

Patients admitted during 1974 and 1975 were treated according to protocol I and patients admitted during 1976 and 1977 according to protocol II. 
Table 1. Patients with diabetic ketoacidosis: data on admission (mean $\pm \mathrm{SD}$ )

\begin{tabular}{lcc}
\hline & Group I & Group II \\
\hline $\mathrm{n}$ & 12 & 12 \\
Age (yr) & $41 \pm 15$ & $34 \pm 15$ \\
Glucose (mmol/1) & $42.3 \pm 11.3$ & $42.5 \pm 18.7$ \\
$\mathrm{pH}$ & $6.89 \pm 0.09$ & $6.98 \pm 0.08$ \\
$\beta$-OH-butyrate (mmol/l) & $11.4 \pm 1.5$ & $11.3 \pm 1.2$ \\
Potassium (mmol/l) & $5.3 \pm 1.8$ & $5.3 \pm 1.7$ \\
& & \\
\hline
\end{tabular}

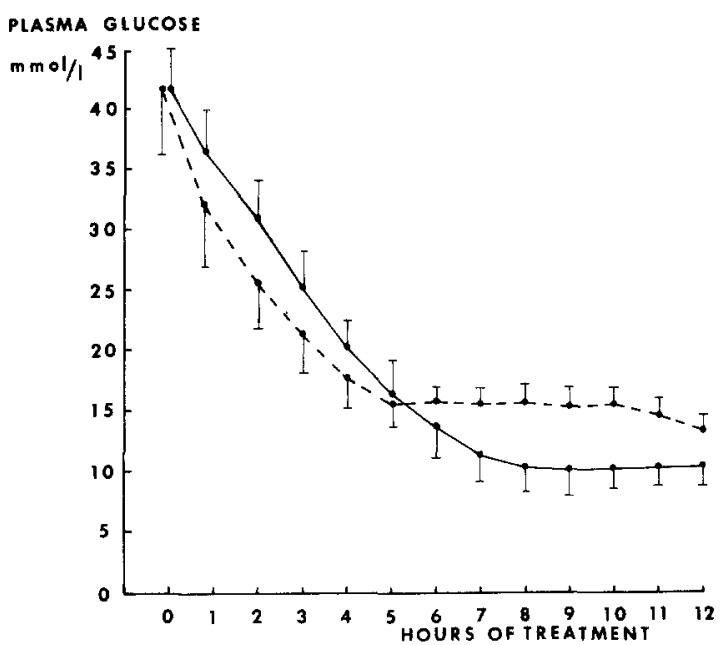

Fig. 1. Plasma glucose concentration (mean \pm SEM) during treatment of diabetic ketoacidosis in two groups of patients. Group I (high insulin dose) is represented by the continuous line and group II (low insulin dose) by the dashed line

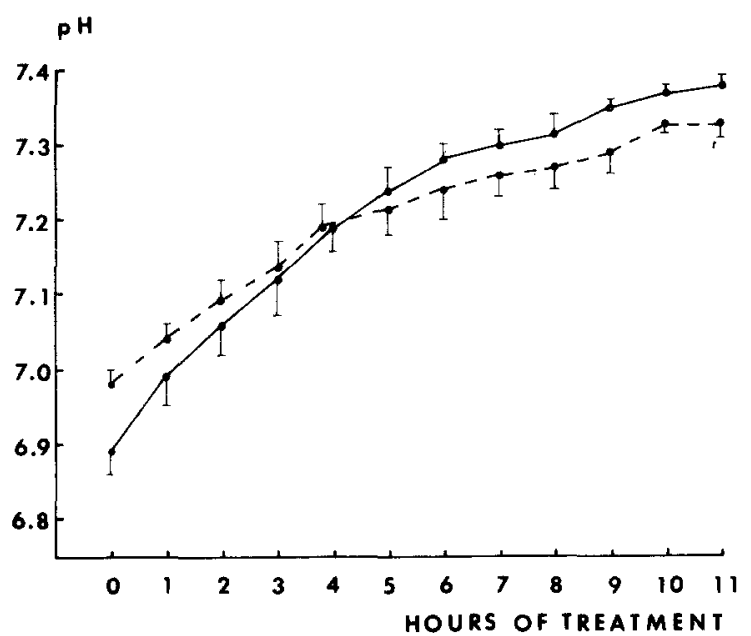

Fig. 2. $\mathrm{pH}$ in arterial blood (mean \pm SEM) during treatment of diabetic ketoacidosis in two groups of patients. Group I (highdose) is represented by the continuous line and group II (lowdose) by the dashed line

\section{Protocol I (High-Dose Insulin)}

a. Insulin. Immediately after the diagnosis had been established insulin (Actrapid ${ }^{\mathrm{R}}$ ) was administered: $40 \mathrm{U}$ IV and $40 \mathrm{U} \mathrm{IM}$. Further insulin was given after the result of the first plasma glucose determination (on admission) became known and subsequently every two hours, each time after a plasma glucose determination. The size of these insulin doses was based on the plasma glucose level: at a plasma glucose of $30 \mathrm{mmol} / \mathrm{l}$ or higher $80 \mathrm{U}$ of insulin was given both IV and IM. At a plasma glucose below $30 \mathrm{mmol} / \mathrm{l}$ $40 \mathrm{U}$ of insulin was given both IV and IM. When the plasma glucose concentration had decreased in two hours by $25 \%$ or more no insulin was administered in the next two hours. The patients treated according to this protocol received $260 \pm 60$ (mean \pm SD) $\mathrm{U}$ of insulin in the first 6 hours.

b. Intravenous Fluid Therapy was started with $103 \mathrm{mmol} / \mathrm{l}$ sodium chloride, $3000 \mathrm{ml}$ in the first 3 hours. If the initial $\mathrm{pH}$ was 7.0 or lower $1000 \mathrm{ml} \mathrm{NaCl}(103 \mathrm{mmol} / \mathrm{l})$ was replaced once by $1000 \mathrm{ml}$ sodium bicarbonate $(167 \mathrm{mmol} / \mathrm{l})$. Thus, all patients treated according to this scheme received $167 \mathrm{mmol}$ bicarbonate. In the following 3 hours $2000 \mathrm{ml} \mathrm{NaCl}(103 \mathrm{mmol} / \mathrm{l})$ was infused and after this the rate of infusion was $500 \mathrm{ml} /$ hour. When the plasma glucose concentration reached $15 \mathrm{mmol} / \mathrm{l}$ the sodium chloride solution was replaced by glucose $(5 \mathrm{~g} / 100 \mathrm{ml})$ mixed with $20 \mathrm{U}$ of insulin in every $500 \mathrm{ml}$.

c. Potassium Supplementation. If the plasma potassium concentration fell below $5.0 \mathrm{mmol} / \mathrm{l}, 15 \mathrm{mmol}$ of potassium chloride was added to every $500 \mathrm{ml}$ of infusion fluid.

\section{Protocol II (Low-Dose Insulin)}

a. Insulin. After diagnosis, insulin was given by continuous intravenous infusion of $8 \mathrm{U} /$ hour. For this purpose $40 \mathrm{U}(1 \mathrm{ml})$ of Actrapid $^{\text {है }}$ was mixed in a $60 \mathrm{ml}$ syringe with $34 \mathrm{ml}$ of saline $(0.154 \mathrm{mmol} / \mathrm{l})$ and $15 \mathrm{ml}$ of a plasma protein solution containing human albumin $35 \mathrm{~g} / \mathrm{l}$. The syringe was placed in an infusion pump (Sage model 242) and connected to the patients' intravenous catheter by a Talas Monitor-line, internal diameter $1 \mathrm{~mm}$.

$b$. The schedule of intravenous fluid therapy was the same as in protocol I, except that no bicarbonate was given. When plasma glucose reached $15 \mathrm{mmol} / 1$ the $\mathrm{NaCl}$ infusion was changed to glucose, $5 \mathrm{~g} / 100 \mathrm{ml}$; insulin adminstration by the infusion pump at the rate of $8 \mathrm{U} /$ hour was not altered.

c. The scheme of potassium supplementation was the same as in protocol I.

The treatment was continued until the arterial $\mathrm{pH}$ had reached 7.35 (and the ketone reaction in plasma diluted $1: 2$ was negative).

During both treatment regimes venous blood was obtained at hourly intervals for measurements of plasma glucose, electrolytes, 3-hydroxybutyrate and, in some patients, insulin. The $\mathrm{pH}$ was measured in arterial blood every hour.

\section{Patients}

Twelve patients (group I) were treated with protocol I during 21 episodes of ketoacidosis. Protocol II with low-dose insulin was also used in 12 patients (group II) in 25 episodes of ketoacidosis. For the purpose of this study only one episode for every patient, the one with the lowest $\mathrm{pH}$, was used. Two patients were treated according to both protocol I and protocol II.

In group I consciousness was depressed in 11 patients; 4 patients were in coma. 


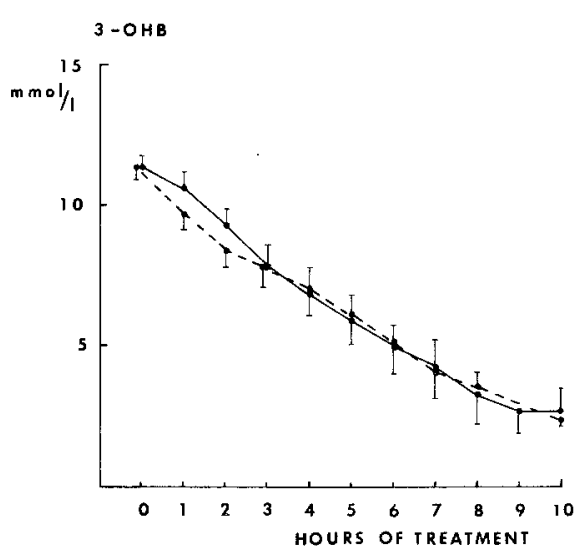

Fig. 3. Plasma 3-hydroxybutyrate concentration (mean \pm SEM) during treatment of diabetic ketoacidosis in two groups of patients. Group I (high-dose) is represented by the continuous line and group II (low-dose) by the dashed line

9 Patients of group II had a depressed conscious level, 2 were in coma. Except for 1 patient in group I (patient 9), who was on anticonvulsant therapy for epilepsy, none of the patients had any associated disease or used any other drugs.

There were no significant differences between the data on admission of the groups as shown in Table 1.

\section{Analytical Methods}

Plasma glucose was measured with the automated method of Hoffman [13]. The $\mathrm{pH}$ in arterial blood was estimated with a Corning $\mathrm{pH}$-blood gas analyser. Plasma ketones in serial dilution were measured by the nitroprusside method (Ketur-test). An enzymatic method was used for the measurement of 3-hydroxybutyrate in a perchloric acid extract of plasma [14]. Plasma insulin in patients without insulin binding antibodies was measured by radioimmunoassay (double-antibody solid-phase method) [15]. In patients with antibodies the concentration of free insulin was measured by a modification of the method of Nakagawa et al. [16], using polyethyleneglycol $(25 \mathrm{~g} / 100 \mathrm{ml})$ for the precipitation of the insulinantibody complexes.

Results are presented as mean \pm SEM. For statistical evaluation Wilcoxon's test for unpaired data was used.

\section{Results}

\section{Plasma Glucose}

There was a rapid fall in plasma glucose with either regime (Fig. 1). In the first two hours plasma glucose decreased in group I by $11.3 \pm 3.0 \mathrm{mmol} / 1$ and in group II by $16.9 \pm 2.7 \mathrm{mmol} / \mathrm{l}(\mathrm{p}>0.1)$. The difference between the mean plasma glucose concentrations in the two groups was not statistically significant any time during the first 8 hours.

In group I the glucose concentration reached a lower level than in group II. This was mainly caused by the fact that hypoglycaemia occurred in 4 patients,

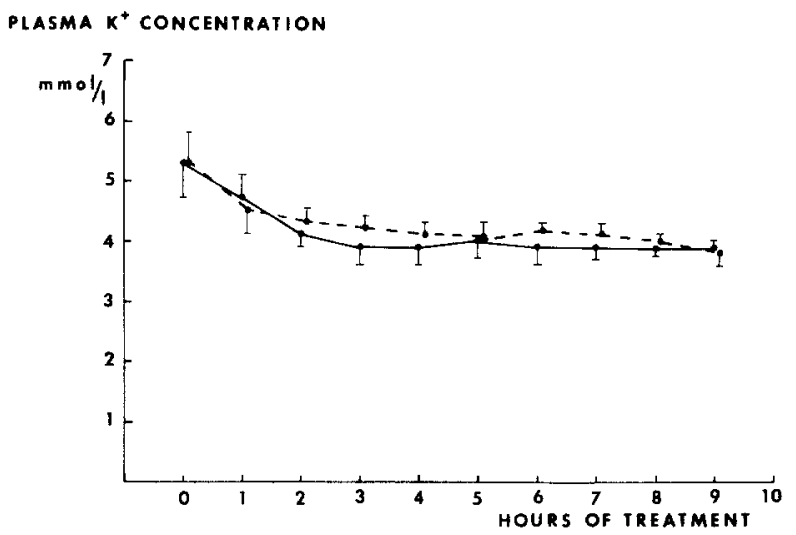

Fig. 4. Plasma potassium concentration (mean \pm SEM) during treatment of diabetic ketoacidosis in two groups of patients. Group I (high-dose) is represented by the continuous line and group II (low-dose) by the dashed line

in whom the attending staff had omitted to replace the saline infusion with glucose in time. When these four patients were left out, there was no significant difference in glucose level between the two groups. All patients of group II were treated stringently according to the protocol and hypoglycaemia did not occur.

\section{Ketoacidosis}

The rise in $\mathrm{pH}$ during both treatments is shown in Fig. 2. The mean rise in $\mathrm{pH}$ in group I during the first 2 hours, in which the bicarbonate was administered, was $0.15 \pm 0.07$. In the same time the $\mathrm{pH}$ in group II (without bicarbonate) rose $0.11 \pm 0.07(\mathrm{p}>0.05)$. There never was a statistically significant difference in the mean $\mathrm{pH}$ between both groups. With the exception of 1 patient of group II, who died, an arterial $\mathrm{ph} \geqslant 7.30$ was reached in all patients of groups I and II within 10 hours. The mean ( \pm SD) time in which this $\mathrm{pH}$ was reached was $6.8 \pm 2.3$ hour in group I and $7.6 \pm 3.4$ hour in group II $(p>0.10)$. From the decrease in concentration of 3-hydroxybutyrate (Fig. 3) it is clear that the effect of both regimes on ketosis was also the same.

\section{Potassium Concentration}

The pattern of the mean plasma potassium concentrations is shown in Fig. 4. On admission potassium levels varied widely. In some patients they were high, but in all cases normal levels were reached within a few hours by no other measures than the treatment of the ketoacidosis. The difference between the mean potassium concentrations in both groups was never significant $(\mathrm{p}>0.1)$. Potassium supplementation 
(mean $\pm \mathrm{SD}$ ) amounted to $98 \pm 43 \mathrm{mmol}$ in group I and $74 \pm 26$ in group $\Pi(p>0.05)$ and was given within 12 hours.

\section{Insulin Concentrations}

No measurements of plasma insulin were made in group I. In 5 patients from group II insulin concentrations were measured 3 to 8 times during treatment. If insulin binding antibodies had been demonstrated the concentration of free insulin was measured. The mean $( \pm \mathrm{SD})$ plasma insulin level during treatment with $8 \mathrm{U}$ of insulin/hour was $121 \pm 46 \mu \mathrm{U}$ / $\mathrm{ml}$ (range 89-200 $\mu \mathrm{U} / \mathrm{ml}$ ).

The presence of insulin binding antibodies did not result in lower (free) insulin concentrations.

\section{Complications}

All patients of group I recovered. Four patients developed hypoglycaemia with plasma glucose concentrations of $2.8 \mathrm{mmol} / \mathrm{l}$ or less. No instances of severe hypokalaemia (potassium level $<2.5 \mathrm{mmol} / \mathrm{l}$ ) were observed.

One patient of group II, a 68 years old male, died. The duration of his ketoacidosis before admission to hospital was probably 5 days and during the last 12 hours he had been in coma. After 9 hours of treatment he died suddenly. All other patients recovered without complications. Hypoglycaemia or hypokalaemia did not occur.

\section{Discussion}

In two other studies $[9,12]$ the efficacy of low-dose insulin treatment of diabetic ketoacidosis was compared in a prospective way with that of the conventional high-dose treatment, and no difference was found. These and almost all other studies on lowdose treatment concern patients with a moderate degree of ketoacidosis, with a mean $\mathrm{pH}$ in the range 7.07 to 7.25 .

In this report the results are described in two consecutive groups of 12 patients each with severe ketoacidosis ( $\mathrm{pH} \leq 7.10$ in all), treated prospectively with a fixed protocol with either high or low-dose insulin. There was no difference in the rate of recovery, neither with regard to the hyperglycaemia, nor with regard to the acidosis and ketosis. This result is all the more remarkable in view of the fact that bicarbonate was administered to all patients in the highdose group.

For the low-dose treatment we chose the continuous intravenous route. With this simple method desired insulin levels are rapidly obtained and maintained.

It appears from the much quoted study of Christensen and Ørskov [17], that glucose uptake in muscle takes place at insulin levels between 20 and $200 \mu \mathrm{U} /$ $\mathrm{ml}$ and that higher insulin concentrations do not bring about a greater effect. Kitabchi et al. [9] reported, that hourly IM injections of $5 \mathrm{U}$ insulin resulted in plasma-insulin concentrations of $80-90 \mu \mathrm{U} / \mathrm{ml}$, which were as effective as a few thousand $\mu \mathrm{U} / \mathrm{ml}$. These very high insulin concentrations can cause a more rapid fall in plasma glucose levels, but do not result in a faster decline of plasma ketones and FFA [18]. Within the range of $20-200 \mu \mathrm{U} / \mathrm{ml}$ it appears, from the study of Piters et al. [11], that insulin concentrations of $130 \mu \mathrm{U} / \mathrm{ml}$ are no more effective in the treatment of the ketoacidosis than concentrations of $50 \mu \mathrm{U} / \mathrm{ml}$. Concentrations of $25 \mu \mathrm{U} / \mathrm{ml}$ were clearly less effective and this concentration is that achieved by continuous IV administration of $2 \mathrm{U} /$ hour. Brown [19] has reported that this insulin dose causes a fall in plasma glucose mainly by inhibition of glucose production, whereas higher doses are necessary for stimulation of glucoseuptake. In our patients insulin levels of $121 \pm 46 \mu \mathrm{U} /$ $\mathrm{ml}$ were achieved with $8 \mathrm{U} /$ hour. Before the start of our study 6 patients with diabetic ketoacidosis had been treated with $4 \mathrm{U} / \mathrm{hour}$. The mean insulin concentration was $85 \pm 45 \mu \mathrm{U} / \mathrm{ml}$, significantly lower than the concentration obtained with $8 \mathrm{U} /$ hour $(\mathrm{p}<0.02)$. The results in one patient treated 5 times with $8 \mathrm{U} /$ hour and 5 times with $4 \mathrm{U} /$ hour with similar mean rates of decline of plasma glucose, are evidence for the equivalence of both dosages. We feel, however, that it is useless and potentially dangerous to search for the lowest possible insulin dose.

From the measurements of free insulin levels in those patients having insulin binding antibodies it appeared that during continuous IV insulin therapy, insulin levels are not influenced by the presence of these antibodies. Asplin and Hartog [20] came to the same conclusion.

During high-dose therapy hypoglycaemia can easily occur if glucose administration is delayed. In group I hypoglycaemia occurred in 4 patients due to the presence of a depot of intramuscular insulin. During the low-dose treatment hypoglycaemia did not occur.

Schade and Eaton [18] have clearly shown, that very high insulin concentrations can result in a greater reduction of the plasma potassium concentration. However, in our two groups, that received the same potassium supplementation, the mean pattern of plasma potassium concentration did not differ.

The cause of sudden death of one patient in group 
II was probably related to the age of the patient and to the long duration of the ketoacidosis before admission.

In conclusion, the present study indicates, that continuous intravenous administration of low-dose insulin ( $8 \mathrm{U} /$ hour) is as effective in the treatment of patients with severe diabetic ketoacidosis as the conventional high-dose therapy and does not give rise to episodes of hypoglycaemia. The use of bicarbonate in general is not necessary.

\section{References}

1. Alberti, K. G. M. M., Hockaday, T. D. R., Turner, R. C.: Small doses of intramuscular insulin in the treatment of diabetic "coma". Lancet 1973 II, 515-522

2. Page, M.M., Alberti, K. G.M.M., Greenwood, R., Gumaa, K. A., Hockaday, T. D. R., Lowy, C., Nabarro, J. D. N., Pyke, D. A., Sönksen, P. H., Watkins, P. J., West, T. E. T.: Treatment of diabetic coma with continuous low-dose infusion of insulin. Br. Med. J. 1974 II, 687-690

3. Kidson, W., Casey, J., Kreagen, E., Lazarus, L.: Treatment of severe diabetes mellitus by insulin infusion. Br. Med. J. 1974 II, 691-694

4. Semple, P.E., White, C., Manderson, W. G.: Continuous intravenous infusion of small doses insulin in treatment of diabetic ketoacidosis. Br. Med. J. 1974 II, 694-698

5. Moseley, J.: Diabetic crises in children treated with small doses of intramuscular insulin. Br. Med. J. 1975 I, 59-61

6. Soler, N. G., FitzGerald, M. G., Wright, A. D., Malins, J. M.: Comparative study of different insulin regimens in management of diabetic ketoacidosis. Lancet 1975 II, 1221-1224

7. Clumeck, N., de Troyer, A., Naeije, R., Somers, G., Smekens, L., Balasse, E. D.: Treatment of diabetic coma with small intravenous insulin boluses. Br. Med. J. 1976 II, 394-396

8. Hannan, T. J., Stathers, G. M.: Constant low-dose insulin infusion in severe diabetes mellitus. Med. J. Aust. 1976 I, 11-13

9. Kitabchi, A. E., Ayyagari, V., Guerra, S. M., Medical house staff.: The efficacy of low-dose versus conventional therapy of insulin for treatment of diabetic ketoacidosis. Ann. Intern. Med. 84, 633-638 (1976)

10. Fisher, J. N., Shahshahani, M.N., Kitabchi, A. E.: Diabetic Ketoacidosis: Low-dose insulin therapy by various routes. $\mathrm{N}$. Engl. J. Med. 297, 238-241 (1977)
11. Piters, K. M., Kumar, D., Pei, E., Bessman, A. N.: Comparison of continuous and intermittent intravenous insulin therapies for diabetic ketoacidosis. Diabetologia 13, 317-321 (1977)

12. Heber, D., Molitch, M. E., Sperling, M. A.: Low-dose continuous insulin therapy for diabetic ketoacidosis. Prospective comparison with "conventional" insulin therapy. Arch. Intern. Med. 137, 1377-1380 (1977)

13. Hoffman, W. S.: A rapid photoelectric method for the determination of glucose in blood and urine. J. Biol. Chem. 120, 51-55 (1937)

14. Mellanby, J., Williamson, D. M.: In: Methoden der enzymatischen Analyse. Bergmeyer, H. E. (Ed.) - pp 1883-1886. Weinheim/Bergstr.: Verlag Chemie 1974

15. Hollander, F. D. den, Schuurs, A.H.W.M., Hell, H. van: Radioimmunoassays for human gonadotrophins and insulin employing a "double-antibody solid-phase" technique. J. Immunol. Methods 1972 I, 247-262

16. Nakagawa, S., Nakayama, H., Sasaki, T., Yochino, K., Yu, Y. Y., Shinozaki, K., Aoki, S., Hashimo, K.: A simple method for the determination of serum free insulin levels in insulintreated patients. Diabetes 22, 590-600 (1973)

17. Christensen, N. J., Ørskov, H.: The relation between endogenous serum insulin concentration and glucose uptake in the forearm muscles of non diabetics. J. Clin. Invest. 47, 1262-1268 (1968)

18. Schade, D. S., Eaton, Ph.: Dose response to insulin in man: differential effects on glucose and ketone body regulation. J. Clin. Endocrinol. Metab. 44, 1038-1053 (1977)

19. Brown, P. M., Tompkins, C. V., Juul, S., Sönksen, P. H.: Mechanism of action of insulin in diabetic patients: a doserelated effect on glucose production and utilisation. Br. Med. J. 1978 I, 1239-1242

20. Asplin, C. M., Hartog, M.: Serum free insulin concentrations during the treatment of diabetic coma and precoma with low dose intramuscular insulin. Diabetologia 13, 475-480 (1977)

Received: September 11, 1978

and in revised form: March 15, 1979

\section{J. A. Lutterman}

Department of Internal Medicine

St. Radboud Hospital

Geert Grooteplein Zuid 16

$6500 \mathrm{HB}$ Nijmegen

The Netherlands 